DOI 10.15593/2224-9354/2018.1.12

УДК 908.470 .53

\title{
О.В. Протопопова
}

\section{ТЕКСТЫ О ПУТЕШЕСТВИЯХ В ПЕРМСКОМ КРАЕВЕДЧЕСКОМ ЖУРНАЛЕ: ФУНКЦИИ И РЕАЛИЗАЦИЯ}

\begin{abstract}
Объектом изучения является успешный краеведческий журнал «Мы - земляки», издаваемый в Перми. Он приобщает читателей к общенациональным и уральским духовным и материальным ценностям, способствует патриотическому воспитанию земляков, их историко-культурному просвещению. Важную роль при этом играют публикации в жанре травелога - предмета данного исследования, цель которого состоит в выявлении функций документальных рассказов о путешествиях по малой родине. Установлено, что в иерархии интенций травелога главной является нарративная, подкрепляемая дополнительными коммуникативными целями: познавательно-просветительской, оценки и контактоустановления. Интенция нарратива реализуется успешно благодаря презентации реальных событий по определенному коммуникативному сценарию соответственно маршруту и хронологии путешествия. Этапы и результаты познавательной деятельности повествователя-просветителя в тексте представлены не только вербально, но и визуально. Удачное сочетание иконических и языковых приемов усиливает информативность повествования и его воздействие на адресата. Документальности и достоверности травелога не вредит проявление субъективного авторского отношения к увиденному. Искреннее повествование как о красоте природы и памятников архитектуры, так и о их разрушении и загрязнении людьми апеллирует к патриотическим чувствам пермяков и способствуют повышению уровня их экологической культуры. Эффрект усиливается за счет использования средств установления контакта с читателями. В результате анализа выявлена также новая дополнительная интенция документального травелога - рекламная: автор явно стремится повысить имидж описываемых объектов и убедить читателей в привлекательности этих мест для туризма. Наш вывод о воплощении в травелоге еще и рекламной интенции вполне согласуется, во-первых, с двуединой природой публицистического стиля - воздействующе-информирующей, а во-вторых - с реализацией в рекламном тексте апеллятивно-эмоциональной, репрезентативной и воздействующе-коммуникативных функций.

Ключевые слова: региональный краеведческий журнал, травелог документальный, иерархия интенций, рекламная функция.
\end{abstract}

Важность изучения рассказов о путешествиях из краеведческих изданий определяется потребностью научно обобщить опыт культурно-просветительской деятельности региональных СМИ. Объектом настоящего исследования выступает документальный травелог ${ }^{*}$ - текст о путешествиях на реальной, достоверной основе, рассказ о совершенной поездке, экспедиции. Это повествование, подкрепленное историческими и географическими свидетельствами, не чуждое рефлексии автора по поводу ожидания и реально увиденного [1]. Предмет нашего изучения - травелоги документального характера из пермского журнала «Мы - земляки» за 2010 год. Цель анализа состоит в выявлении функций документального травелога названного издания.

\section{(C) Протопопова О.В., 2018}

Протопопова Ольга Витальевна - доцент кафедры иностранных языков, лингвистики и перевода ФГБОУ ВО «Пермский национальный исследовательский политехнический университет», e-mail: olgaprotopopova@yandex.ru.

* Параллельно используется вариант написания «трэвелог». 
«Мы - земляки» являет собой пример успешного современного регионального журнала по краеведению. В настоящее время российская краеведческая периодика представлена почти 200 журналами, альманахами и сборниками из более чем 50 регионов. В этом видится продолжение дореволюционной традиции местного краеведения, направленной на изучение родного региона, охрану его культурного и природного наследия, на сохранение исторической памяти. Подчеркнем положительную роль Всероссийской программы поддержки краеведческих журналов, направленную на повышение общественного и культурного статуса региональной периодики, на выявление и сохранение российских историко-культурных объектов.

Издаваемый с 2009 года, единственный в Прикамье журнал по краеведению «Мы - земляки» позиционирует себя как издание о Пермском крае и его жителях под девизом «Знаем все о малой родине». Постоянно помещаемые материалы по истории и современности Прикамья адресованы прежде всего молодежи и направлены на освещение и сохранение культурного и природного наследия региона. С этой целью редакция регулярно организует викторину «Знаем все о малой родине». Как сказано в положении о викторине для учащейся молодежи Пермского края, мероприятие призвано способствовать патриотическому воспитанию, углублению знаний читателей об истории, литературе, культуре Прикамья, стимулировать интерес к местной периодике, а также формировать и закрепить познавательный интерес к культурной и духовной жизни региона. Ответы на вопросы викторины в основном можно найти на страницах журнала [2, с. 94]. Через просвещение земляков издание успешно решает воспитательно-пропагандистские задачи, способствуя приобщению читателей к общенациональным и местным, уральским, духовным и материальным ценностям.

Уделяя большое внимание развитию внутреннего туризма, в разделе «Непознанное Прикамье» журнал постоянно печатает интересные рассказы о разнообразных путешествиях и экспедициях по малой родине, чем всемерно способствует гражданскому и патриотическому воспитанию пермяков. В колонке «От редактора» Галина Костарева пишет: «Важно на какое-то время почувствовать себя в роли гостя и увидеть что-то новое, обогатить себя свежими знаниями и впечатлениями». Тем более, что в Пермском крае можно увидеть и узнать «столько интересного, что воспоминаний хватит на целый год!!!» [3, с. 3].

Наряду с этим в журнале часто встречаются публикации о посещении пермяками зарубежных стран, призванные формировать их привлекательный образ в общественном сознании россиян, а значит, способствуют толерантному и гуманному восприятию многообразия мира. В качестве примера можно назвать статью «Зимние сказки Лапландии» [13]. Тексты травелогов, посвященные путешествиям в основном по Уралу, будучи малоизученными, но весьма показательными, послужили материалом данного исследования. 
Объем понятия «травелог» сегодня очень расплывчат и широк: с его помощью принято обозначать разножанровую «литературу скитаний» - от дневников, отчетов, мемуаров до очерков, путевых заметок, блогов о совершенных путешествиях. Такие тексты в настоящее время активно изучаются с разных позиций социологами, географами, историками, антропологами, а также филологами и журналистами. Актуальность проблематики подтверждается наличием многочисленных публикаций и обсуждением темы научным сообществом, например на конференции «Русский травелог XVII-XX вв.» [4]; плодотворно работала секция «Травелог как тип медиатекста» на I Международной научно-практической конференции «Язык в координатах массмедиа» (Варна, 2016 г.) [5]. Исследуется стиль трэвел-изданий как части журналистики сферы досуга [6]. При этом все еще недостаточно внимания уделяется специфике травелога документально-регионального, что и призвано компенсировать данное исследование.

Необходимость всестороннего изучения жанра объясняется его сложным характером, который детерминируется особенностями интенции. В частности, применительно к документальному травелогу, на наш взгляд, следует иметь в виду не плоскую шкалу (ср. с [7]), а иерархию интенций: доминантной является нарративная, подкрепляемая и дополняемая другими коммуникативными целями - познавательно-просветительскими, эмоциональной и рациональной оценки, контактоустановления. Доминантная интенция обязывает автора повествовать о событиях путешествия и описывать наблюдаемые при этом разнообразные объекты, стремясь представить не сухой деловой отчет об увиденном, а увлекательный рассказ о своих перемещениях в пространстве. Для успешной реализации нарративной интенции автор отбирает и организует реальные события и эпизоды по определенному коммуникативному сценарию, обычно в соответствии с хронологией и маршрутом путешествия. Благодаря этому в тексте травелога вербализуются результаты собственной познавательной деятельности повествователя, который одновременно выступает и в роли просветителя читателей. Эпизоды и события путешествия по определенной территории логично рассматривать как этапы познания достопримечательных мест.

Документальный характер травелога предопределяет вербальную демонстрацию представленных в тексте географических объектов, природных явлений, достопримечательностей культуры, местных традиций, например фольклорных или кулинарных; описания способов перемещения путешественников в пространстве (по суше, воде, воздуху); формулировки выводов, подведения итогов, презентации планов и перспектив дальнейших путешествий.

Достоверность совершенному путешествию придает обязательная красочная визуализация объектов травелога с помощью фото, схем, карт и т.п. Отметим многочисленные профессионально выполненные иллюстрации к материалам журнала «Мы - земляки», играющие репрезентирующую роль, что делает медиатравелоги креолизованными текстами. Сложная поликодовая форма травелогов 
позволяет успешнее и эффективнее реализовывать авторский замысел: не только вербально достоверно доносить до адресата сведения об увиденном, но и придавать объектам наблюдения привлекательный вид с помощью визуальных изобразительных средства. Умелое сочетание языковых и иконических приемов, их взаимодействие обогащает, уточняет информативность травелога, увлекает читателей, а значит, усиливает воздействие публикации.

Выражение доминантной интенции - осведомления о территории - осуществляется, прежде всего, коммуникативными действиями ее описаний (пейзажами), чтобы реалистично отразить свойства того пространства наблюдения, которые обнаруживаются в поле зрения путешественника. Особо пристальное внимание уделяется естественно-географическим характеристикам территории: «Выяснить, где находится крайняя восточная точка континентальной Европы, помогли географы из госуниверситета. Оказалась, что она не так уж далеко от Пермского края, а именно - в верховьях реки Малая Уса и имеет координаты 67 градусов 40 минут северной широты и 66 градусов 15 минут восточной долготы. На самом деле - это горы Полярного Урала. Ближайший населенный пункт - город Воркута, он находится примерно в 100 километрах от точки» [8, с. 68].

Номинации таких характеристик представлены географическими наименованиями территорий, названиями их частей, предлогами места, благодаря которым уточняется пространственное расположение объектов: в Воркуте, в Европе, через границу Европы и Азии и др. Помимо локативов, тексты о путешествиях вообще изобилуют именами собственными, и не только топонимами, но и антропонимами, которые необходимы как для называния участников текущих, так и произошедших ранее событий, например: Строгановы, Стефан Великопермский, Питирим. С учетом фактора адресата и просветительской направленности травелога недостаточно известные и/или новые для читателя имена собственные поясняются: Усть-Вымь - когда-то духовный и религиозный центр этого северного края; Сольвычегорск - родовое гнездо Строгановых.

Во фрагментах повествования о перемещениях персонажей обычно называются средства передвижения (вездеходы, грузовая машина), перечисляются виды грузов (оборудование, провизия, дрова, запас горючего), проделанные действия (погрузили, устроились, уселись, двинулись). Пример: «Мы благополучно доехали до места назначения, забрались на Белую гору, и тут случилось чудо» [9, с. 89]. Читатель дополнительно узнает еще и об отношении автора к увиденному, в данном случае - о его восхищении.

Документальный характер травелога означает, что журналист информирует читателей о реально существующих объектах, известных и доступных в разной степени, а значит, выполняет просветительскую функцию. Путешествие выступает средством познания нового, неизведанного. Из текстов о временных перемещениях человека в другие места адресат - через посредство автора текста - 
черпает в интересной и достаточно доступной форме сведения о географии, истории, культуре. При этом сам повествователь не остается равнодушным, делясь собственными эмоциями с читателями, вовлекая их в процесс познания.

Несомненно, что с учетом фактора адресата журналист излагает фактуальную информацию научно-популярно: с одной стороны, стремясь к достоверности, точности, с другой - обеспечивая большую простоту, доступность и увлекательность сообщения. Так реализуется принцип научно-популярного изложения - его доступность и наглядность [10]. Выбор объектов путешествия осуществляется с учетом степени их известности для читателей, что позволяет журналисту создавать интересный и яркий травелог, познавательный и развлекательный одновременно. Поэтому автор прибегает к многочисленным выразительно-изобразительным средствам языка разных функциональных стилей.

Стремление узнать новое, неизведанное толкает путешественника побывать в уникальных местах и поделиться впечатлениями с другими: «Итак, план дерзок, фантастичен, красив и безумен. Наша компания должна встретить Новый год ПЕРВОЙ в Европе, т.е. «всего лишь» оказаться в новогоднюю ночь на самой ВОСТОЧНОЙ точке континентальной Европы. А через 12 месяцев ПОСЛЕДНИМИ из европейцев этот год проводить на самой ЗАПАДНОЙ точке материка. Таким образом, команда намеревалась прожить самый длинный год в Европе! Вот такие грандиозные планы, достойные книги рекордов Гиннесса» $[8$, c. 68]. Как видим, сообщая страноведческие знания, журналист явно соперничает с фотографом, который запечатлевает прекрасные объекты, и живописует их вербально. С этой целью используются разнообразные выразительные средства, прежде всего лексические. Приведем лишь один пример ландшафтного описания: «Неизгладимое впечатление производит Яйвинская ГРЭС. Если позволяет время, стоит подъехать к карьеру Известняк, замечательному цветом наполняющей его воды - бирюзовой, лазурной» [9, с. 92]. Прилагательные ярко определяют детали объектов наблюдения.

Документальность и достоверность повествования отнюдь не нарушается проявлением субъективного, личностного начала: оно лишь подчеркивает активность, заинтересованность журналиста. Автор открыто выражает свои эмоции, делясь ими с читателями, чтобы разнообразить процесс познания и положительно воздействовать на адресата, увлечь его. Поэтому важную роль в травелоге играет оценочность, которая помогает передать впечатление автора от увиденного, например восхищение: живописные (горы), удивительная (забота), причудливый (рельеф), замечательные (пейзажи), иикарные (дома).

Вместе с тем интенция документировать наблюдаемые объекты обусловливает выражение и негативной авторской оценки, сожаления и разочарования от бесхозяйственности и разрухи: «Представляете, удивительная красота скал, стройные кедры, замечательные природные пейзажи, все это завораживает, если смотреть издалека. А подходишь ближе - то тут, то там мусор, грязь! Искреннее негодование и возмущение вызывает то, как загряз- 
нили люди это уникальное место» [11, с. 91]. Автор обращается с косвенным призывом сберегать первозданную природу: «Неужели так сложно не оставлять мусор и не портить эти природные объекты?» [11, с. 91].

Мотив воспитания патриотизма и повышения уровня экологической культуры у земляков ярко проявляется в травелогах, когда речь заходит о состоянии окружающей среды, о памятниках природы и их бедах. Видя загрязнение красивейших ландшафтов или разрушение зданий и построек и т.п., журналисты с искренним негодованием и возмущением сообщают об этом: «А некоторые умудряются на вершину притащить мангал и прямо там пожарить шашлыки...» [11, с. 93]. С горьким чувством автор описывает вид необитаемых строений в горнозаводском Урале: «Заброшенная Нижняя Губаха производит удручающее впечатление. Дома большей частью разрушеньл... Ее разрушение происходило постепенно. Шахты закрыли... Местное население покинуло этот в прошлом великолепный город с шикарными сталинскими домами» $[11$, с. 92]. Чувство сожаления и разочарования от увиденного усиливается благодаря антитезе с былым великолепием объекта.

Рассмотрим поучительный пример бережного и почтительного отношения к окружающему миру уральских аборигенов-зырян, которые «не ощущали себя покорителями и властителями природы. Могли, например, в церкви, после удачного лесного похода, заказать панихиду... по убитому медведю. Удивительно уважение к преклонению перед мощью, величием леса и его обитателей» [14, с. 71]. Очевидна и эффективна воспитательная направленность фрагмента.

Достаточно ярко в рассмотренных травелогах проявляется функция контактоустановления, прямая обращенность к читателям, чтобы они не оставались равнодушными и безучастными к сообщаемому. Так, в приведенных фрагментах обнаруживается средство установления контакта с читателем (представляете). В другом случае с этой же целью использовано вставное предложение (вы nомните?). Типичным способом вовлечения читателей в описываемые события и создания эффекта присутствия оказался вопросно-ответный комплекс, например: «Так какие же черты характера прежде всего отличают жителей Кудымкаpa? Глава администрации города ... считает ...» [12, с. 11], «Кто он? Конечно, Санта Клаус!» [13, с. 53]. Весьма существенно способствуют активизации адресата и риторические вопросы, например: «В самом деле, почему нет?» [13, с. 53].

Приведенные примеры показывают, как воплощается авторская установка на получение ответной реакции читателей, на обеспечение обратной связи, т.е. то, как реализуются в травелоге диалогические отношения. Важным средством их выражения и оказываются приемы экспрессивного синтаксиса, причем не только упомянутые вопросительные, но и восклицательные предложения: «Но ведь они там тоже на машинах ездят!» или: «Завелся!» и т.п. Весьма выразительно использовано восклицание в сочетании с парцелляцией: «Никого рядом не было. На сотни верст!» [9, с. 70]. Автор, несомненно, апеллировал к читателям так экспрессивно, чтобы они представили себе уникальность достижения странника. 
Проведенный анализ подтвердил, что в документальных травелогах из пермского журнала «Мы - земляки» успешно реализуется ведущая интенция нарратива, которая дополняется такими коммуникативными целями, как познавательно-просветительская, оценки и установления контакта с читателем. Иначе говоря, журналисты не только с достоверностью осведомляют, информируют адресата об объектах путешествий, но и одновременно воздействуют на него, убеждая в правильности выбора достопримечательных мест, призывая (явно или неявно) посетить их. Таким образом, информирование приобретает несомненную рекламную направленность благодаря повышению имиджа описанных объектов. Этому способствует авторский интерес к освоению пространства путешествия, рефлексия повествователя по поводу увиденного, прямое обращение к читателям с призывом посетить интересные и привлекательные достопримечательности, чтобы лично познать новое и неизведанное. Следовательно, можно сделать вывод о реализации в документальном травелоге еще и рекламной интенции, конечно, специфическим образом, что заслуживает отдельного изучения. Так, в отличие от рекламного объявления, которое воспроизводится многократно устно или письменно, что усиливает психологическое воздействие на адресата, текст травелога прочитывается неопределенное число раз. Обратная связь в этом случае носит весьма вероятностный характер.

Наш вывод о реализации в документальном травелоге еще одной интенции, а именно - рекламной, коммерческо-побудительной, получивший практическое подтверждение в ходе вышеописанного анализа, имеет и теоретическое обоснование, именно в рекламном тексте органично сливаются несколько коммуникативных функций: апеллятивно-эмоциональная, репрезентативная и воздействующая [15, с. 636]. Следует, однако, отметить, что рекламирование объектов путешествий в журнале «Мы - земляки» чаще осуществляется не напрямую, только ради извлечения коммерческой выгоды. Прямой рекламой оказались лишь единичные материалы в жанре травелога, подготовленные отделом туризма фонда «Белый камень», открыто воплощающие прагматику побуждения, например, совершить «Новогоднее путешествие по Пермскому краю» [9].

Для нас очевидно, что эффективно организованный по авторскому сценарию текст о путешествии, в котором наряду с воплощением доминантной нарративной интенции реализованы и вышеназванные дополнительные коммуникативные задачи, приобретает несомненный рекламный характер. Ведь авторский интерес к освоению пространства странствия и придание привлекательности объектам осмотра, обращение к читателям с приглашением их к путешествию, чтобы лично познать новое и неизвестное, повышает имидж описанного в травелоге. Так происходит рекламирование объектов путешествия, однако не всегда прямо, явно.

Тот факт, что и такие рассказы также созданы с учетом всех выявленных принципов порождения документального травелога, - свидетельство наличия рекламной составляющей каждого текста в этом жанре, возможно, однако, 
в разной степени. Как представляется, в обоих случаях при достаточно сходном языковом оформлении травелогов (конечно, с поправкой на авторскую индивидуальность журналиста) цели убеждения в привлекательности достопримечательных мест несколько смещаются. Так, если в материалах фонда «Белый камень» ведущей функцией оказывается привлечение к туризму большого числа пермяков, т.е. ориентация на извлечение коммерческой выгоды, то в остальных случаях авторы прежде всего реализуют культурнопросветительскую, воспитательную интенцию, апеллируя к национальной гордости земляков, а значит, решают важнейшие социальные задачи.

Наш вывод вполне согласуется, во-первых, с двуединой природой публицистического стиля - воздействующе-информационной, которая естественным образом явлена также и в документальных медиатравелогах краеведческого регионального журнала «Мы - земляки». Во-вторых, закономерность такого заключения подтверждается и тем фактом, что реклама реализуется в самых разных жанрах, в том числе не чуждым данной функции оказался и изученный нами травелог документального характера в пермском журнале.

\section{Список литературы}

1. Бондарева А. Литература скитаний [Электронный ресурс] // Октябрь, 2012. - № 7. - URL: http://magazines.russ.ru/october/2012/7/bo18.html (дата обращения: 15.02.2017).

2. Викторина «Знаем все о малой родине» // Мы - земляки. - 2010. № 10 (20). - С. 94-95.

3. Костарева Г. Здравствуйте, земляки! // Мы - земляки. - 2010. № 1-2. - С. 3 .

4. Печерская Т.И. Русский травелог XVII - XX века: материалы всерос. науч. конф. (Новосибирск, 11-12 ноября 2014 г.) // Сибирский филологический журнал. - 2015. - № 1. - С. 261-266.

5. Медиалингвистика. Язык в координатах массмедиа: материалы Междунар. науч.-практ. конф. (Варна, Болгария 6-9 сентября 2016 г.) / С.-Петерб. гос. ун-т; Ин-т «Высшая школа журн. и мас. коммуникации». - СПб., 2016.

6. Стиль трэвел-изданий // Стилистика и литературное редактирование: учеб.: в 2 т. / под ред. Л.Р. Дускаевой. - М.: Юрайт, 2016. - Т. 1. - С. 268-275.

7. Дускаева Л.Р. Научно-просветительская медиаречь: репрезентация коммуникативного сценария трэвел-медиатекстов // Научные ведомости. Сер. Гуманитарные науки. - 2014. - № 26 (197), вып. 14. - С. 85-92.

8. Отмахова А. Путешествие в самый длинный год // Мы - земляки. 2010. - № 1-2.- C. 68-70.

9. Шестакова Е. Новогоднее путешествие по Пермскому краю // Мы земляки. - 2010. - № 12 (22). - С. 86-89.

10. Научно-популярный подстиль // Стилистический энциклопедический словарь русского языка. - М., 2003. - С. 236-242. 
11. Шестакова Е. По уральскому кольцу, или Как мы спасались от жары // Мы - земляки. - 2010. - № 10 (20). - С. 90-93.

12. Тупицын С. Кудымкар - город, в который хочется возвращаться // Мы - земляки. - 2010. - № 12 (22). - С. 10-15.

13. Королева С. Зимние сказки Лапландии // Мы - земляки. - 2010. № 12 (22). - С. 52-55.

14. Отмахова А. Автопутешествие. Сложное и поучительное // Мы земляки. - 2009. - № 6. - С. 70-75.

15. Язык и стиль рекламы // Стилистический энциклопедический словарь русского языка. - М., 2003. - С. 635-642.

\section{References}

1. Bondareva A. Literatura skitanii [Literature of wandering]. Oktiabr', 2012, no. 7, available at: http://magazines.russ.ru/october/2012/7/bo18.html (accessed 15 February 2017).

2. Viktorina "Znaem vse o maloi rodine" ["We know all about home places" quiz]. My-zemliaki, 2010, no. 10 (20), pp. 94-95.

3. Kostareva G. Zdravstvuite, zemliaki! [Hello, countrymen!]. My - zemliaki, 2010, no. 1-2, p. 3.

4. Pecherskaia T.I. Russkii travelog XVII-XX veka [The Russian travelogue of the XVII-XX century]. Sibirskii filologicheskii zhurnal, 2015, no. 1, pp. 261-266.

5. Medialingvistika. Iazyk $\mathrm{v}$ koordinatakh massmedia [Media linguistics. Language in the coordinates of mass media]. Materialy Mezhdunar. nauch.-prakt. konf. (Varna, Bolgariia 6-9 sentiabria 2016 g.) [Materials of the I International Scientific Conference, September 6-9, 2016. Varna, Bulgaria]. St Petersburg, 2016, iss. 5, 290 p.

6. Stil' trevel-izdanii, Stilistika i literaturnoe redaktirovanie [Style of travel publications. Stylistics and literary editing]. Ed. L.R. Duskaeva, Moscow, Iurait, 2016, vol. 1, pp. 268-275.

7. Duskaeva L.R. Nauchno-prosvetitel'skaia mediarech': reprezentatsiia kommunikativnogo stsenariia trevel-mediatekstov [Educational media speech: Representation of the communicative script of travel media texts]. Nauchnye vedomosti. Gumanitarnye nauki, 2014, no. 26 (197), iss. 14, pp. 85-92.

8. Otmakhova A. Puteshestvie v samyi dlinnyi god [Travel into the longest year]. My-zemliaki. 2010, I-II, pp. 68-70.

9. Shestakova E. Novogodnee puteshestvie po Permskomu kraiu [New Year's travel across Perm krai]. My-zemliaki, 2010, no. 12 (22), pp. 86-89.

10. Nauchno-populiarnyi podstil'. Stilisticheskii entsiklopedicheskii slovar' russkogo iazyka [Popular science substyle. Stylistic encyclopedic dictionary of Russian language], Moscow, 2003, pp. 236-242.

11. Shestakova E. Po ural'skomu kol'tsu, ili Kak my spasalis' ot zhary [Around the Ural ring, or how we escaped from the heat]. My - zemliaki, 2010, no. 10 (20), pp. 90-93. 
12. Tupitsin S. Kudymkar - gorod, v kotoryi khochetsia vozvrashchat'sia [Kudymkar - the town you want to return to]. My - zemliaki, 2010, no. 12 (22), pp. $10-15$.

13. Koroleva S. Zimnie skazki Laplandii [Winter fairy tales of Lapland]. My-zemliaki, 2010, no. 12 (22), pp. 52-55.

14. Otmakhova A. Avtoputeshestvie. Slozhnoe i pouchitel'noe [Autotravel. Difficult and instructive]. My-zemliaki, 2009, no. 6, pp. 70-75.

15. Iazyk i stil' reklamy. Stilisticheskii entsiklopedicheskii slovar' russkogo iazyka [Language and style of advertising. Stylistic encyclopedic dictionary of Russian language]. Moscow, 2003, pp. 635-642.

Оригинальность $96 \%$

Получено 07.04.2017 Принято 10.05.2017 Опубликовано 30.03.2018

O.V. Protopopova

\section{TRAVEL TEXTS IN PERM REGIONAL STUDIES JOURNAL: FUNCTIONS AND REALIZATION}

The study is aimed at successful local history journal "My - zemliaki" ("We are countrymen") published in Perm. It discovers the national and Ural spiritual and material values, and facilitates patriotic and historical-cultural education of fellow-citizens. An important part in that process belongs to publications in the form of travelogue which is the subject matter of the investigation aimed at identifying the functions of documentary accounts of travels across home places. It has been established that in the hierarchy of travelogue intentions, the main one is narrative supported by additional communicative objectives: cognitive-educational, appraisal and contact. The narrative intention is realized successfully due to real events presentation through a certain communicative scenario according to the route and chronology of the trip. The stages and results of the cognitive activity of the educator-narrator are presented in the text not only verbally, but also visually. A successful unity of iconic and linguistic devices enhances the information content of the narration and its impact on the recipient. Documentary value and credibility of travelogue are not damaged by the subjective author's attitude to what he/she saw. Sincere narrative about both the beauty of nature and landmarks and their destruction and pollution by people appeal to patriotic sentiments of Perm residents and contributes to higher ecological culture. The effect is enhanced due to means of establishing contact with readers. The analysis has also revealed a new subsidiary intention of travelogue - advertising one: the author evidently seeks to improve the public image of the described objects and convince readers of the attractiveness of these places for tourism. Our conclusion about the travelogue advertising intention firstly agrees with twofold nature of journalistic style (influencing and informing one), and secondly, with realization of appealingemotional, representative and influencing-communicative functions in the advertising text.

Keywords: regional studies journal, documentary travelogue, intention hierarchy, advertising function.

Olga V. Protopopova - Associate Professor, Dept. of Foreign Languages, Linguistics and Translation, Perm National Research Polytechnic University, e-mail: olgaprotopopova@yandex.ru.

Received 07.04.2017 Accepted 10.05.2017 Published 30.03.2018 